\title{
Review Article \\ Stem Cell Therapy in Bladder Dysfunction: Where Are We? And Where Do We Have to Go?
}

\author{
Jae Heon Kim, ${ }^{1}$ Sang-Rae Lee, ${ }^{2}$ Yun Seob Song, ${ }^{1}$ and Hong Jun Lee ${ }^{3}$ \\ ${ }^{1}$ Department of Urology, Soonchunhyang School of Medicine, Seoul 140-743, Republic of Korea \\ ${ }^{2}$ National Primate Research Center, Korea Research Institute of Bioscience and Biotechnology, Ochang 363-883, Republic of Korea \\ ${ }^{3}$ Medical Research Institute, Chung-Ang School of Medicine, Seoul 156-756, Republic of Korea \\ Correspondence should be addressed to Yun Seob Song; yssong@schmc.ac.kr and Hong Jun Lee; leehj71@gmail.com
}

Received 15 June 2013; Revised 7 August 2013; Accepted 7 August 2013

Academic Editor: Ken-ichi Isobe

Copyright (c) 2013 Jae Heon Kim et al. This is an open access article distributed under the Creative Commons Attribution License, which permits unrestricted use, distribution, and reproduction in any medium, provided the original work is properly cited.

To date, stem cell therapy for the bladder has been conducted mainly on an experimental basis in the areas of bladder dysfunction. The therapeutic efficacy of stem cells was originally thought to be derived from their ability to differentiate into various cell types. Studies about stem cell therapy for bladder dysfunction have been limited to an experimental basis and have been less focused than bladder regeneration. Bladder dysfunction was listed in MESH as "urinary bladder neck obstruction", "urinary bladder, overactive", and "urinary bladder, neurogenic". Using those keywords, several articles were searched and studied. The bladder dysfunction model includes bladder outlet obstruction, cryoinjured, diabetes, ischemia, and spinal cord injury. Adipose derived stem cells (ADSCs), bone marrow stem cells (BMSCs), and skeletal muscle derived stem cells (SkMSCs) are used for transplantation to treat bladder dysfunction. The main mechanisms of stem cells to reconstitute or restore bladder dysfunction are migration, differentiation, and paracrine effects. The aim of this study is to review the stem cell therapy for bladder dysfunction and to provide the status of stem cell therapy for bladder dysfunction.

\section{Introduction}

Although numerous treatments for bladder dysfunction including bladder overactivity or underactivity have previously been developed, the improvement in voiding dysfunction is not been fully achieved. Stem cells are defined as cells with an ability to propagate themselves through self-renewal and generate mature cells of multiple lineages through differentiation [1]. Given their unique abilities of site, specific migration, plasticity and potential for tissue repair or regeneration, stem cells and their relationship to repair injury or damage in various organ systems have recent interest.

For the bladder dysfunction, bladder outlet obstruction (BOO) is a well-known and well-established bladder dysfunction model. Other bladder dysfunction models are still at an immature state. Medical and surgical efforts to treat and prevent $\mathrm{BOO}$ are ongoing, as are studies to better understand the effects and clear mechanisms of $\mathrm{BOO}$ at a cellular level.

Mesenchymal stem cells (MSCs) augment healing through cell replacement and stimulation of cell proliferation and angiogenesis. While numerous reports have shown the ability of MSCs to engraft tissues such as lung, liver, heart, and brain, data is still scarce about the repair of bladder dysfunction [2-4].

The aim of this review is to provide the current status of stem cell therapy for bladder dysfunction and also to discuss future prospective on this issue.

\section{Stem Cells for Treatment of Bladder Dysfunction}

MSCs are self-renewing cells with pluripotent capacity to differentiate into various cell types including osteoblasts, chondrocytes, myocytes, adipocytes, and neurons [5].

While all MSCs including bone marrow-derived stem cells (BM-MSCs), skeletal muscle-derived stem cells (SkMSCs), and adipose tissue-derived stem cells (ADSCs) exhibit similar biological properties and therapeutic capabilities, their availability and scalability differ greatly according to therapeutic purpose. For example, while SkMSCs require a 
long expansion time with complicated isolation procedure, ADSCs can be prepared within hours.

ADSCs are mesenchymal stromal cells found in the perivascular space of adipose tissue. ADSCs have the advantage of abundance and easy access when compared with other stem cell types [6]. ADSCs express common stem cell surface markers, genes, and differentiation potentials as MSCs [7]. ADSCs have demonstrated efficacy in experimental studies of urologic conditions $[8,9]$.

SkMSCs are used mainly in artificial injured model including pelvic nerve injury $[10,11]$. As a stem cell source of autologous transplantation, SkMSCs have several advantages because skeletal muscle is the largest organ in the body and can be obtained relatively easily and safely. One of other advantages of SkMSCs is that they can be harvested easily during surgery.

Cells in the CD $34^{+} / \mathrm{CD}_{4} 5^{-}$fraction (Sk-34 cells) and $\mathrm{CD}^{-} / \mathrm{CD} 45^{-}$fraction (Sk-DN cells) are able to synchronously reconstitute nerve-muscle blood vessel units after transplantation. Transplantation of SkMSCs causes significant functional recovery through cellular differentiation into skeletal muscle cells, vascular cells (vascular smooth muscle cells, pericytes, and endothelial cells), and peripheral nervous cells (Schwann cells and perineurium) $[12,13]$.

\section{Mechanisms of Stem Cell in Recovery of Bladder Dysfunction}

Stem cells (SCs) are self-renewing adult stem cells with multipotent differentiation potential. SCs can become many types of tissues either via transdifferentiation or via cell fusion and allow the regeneration and functional restoration [14] and are an important source for cell replacement [15]. They can serve as vehicles for gene transfer, proliferate, and differentiate into bladder smooth muscle cells to repopulate damaged bladder.

3.1. Migration. Recruitment of SCs to the bladder in BOO appears to be associated with increased blood flow and decreased tissue hypoxia, which contributes to improvement in histopathological and functional parameters [16].

MSCs are recruited to inflammation, ischemia, or damaged sites in response to specific chemokines expressed by damaged tissue [17]. A large body of literature exists in the roles of by recruited stem cells in a number of different organ systems and also it is demonstrated in injured bladder, too [18-21].

3.2. Differentiation. The ideal mechanism of stem cell therapy is differentiation, but only a few studies have demonstrated real differentiation into bladder smooth muscle (Table 1). Bladder regeneration by differentiation has been frequently reported in nonpathogenic bladder model. Differentiation pathway plays at most a minor role in the therapeutic effect by SCs transplantation. One explanation is the immortal strand hypothesis [22]. Labeled DNA in dividing cells will be quickly diluted by cell divisions but will be retained for much longer periods in slowly dividing stem cells. If the segregation of sister chromatids into stem cell daughters is not random, and if the stem cell retains the older unlabeled template strands, then the stem cell will lose all labels by the second division after administration of the label as a pulse.

Successful differentiation of stem cells into smooth muscle for bladder repair and replacement was reported by several studies in non-pathogenic model for tissue regeneration $[23,24]$.

3.3. Paracrine Effect. While differentiation has long been considered the main mechanism, it is logical to hypothesize that paracrine release of cytokines and growth factors by transplanted MSCs or their neighboring cells is responsible for the observed effects.

In this regard, SCs secretory factors have been shown to exert therapeutic effects by the modulation of local and systematic inflammatory responses, the stimulation of local tissue regeneration, and/or recruitment of host cells. MSCs themselves could not substitute the damaged cells directly but secrete a growth factor and contribute to reducing fibrosis through paracrine mechanisms [25].

BM-MSCs or ADSCs could secrete many growth factors including hepatic growth factor (HGF), nerve growth factor (NGF), brain-derived growth factor (BDNF), glialderived growth factor (GDNF), insulin-like growth factor (IGF), vascular endothelial growth factor (VEGF), and ciliary neurotrophic growth factor (CNTF) [26] and play an essential part in the antifibrosis effects in injured organ, which implies that reducing fibrosis is managed by paracrine mechanisms rather than by cell incorporation [27-29]. Among the growth factors, HGF is a potent mitogen for hepatocytes, is secreted by MSCs, plays an essential part in the angiogenesis and regeneration of the tissue, and acts as a potent antifibrotic agent $[30,31]$.

In addition to antifibrotic mechanisms, BM-MSCs or ADSCs may provide antioxidant chemicals, free radical scavengers and heat shock proteins in ischemic tissue [32].

\section{Stem Cell Therapy in Pathologic Model of Bladder Dysfunction}

To date, the BOO model is the prominent model for bladder dysfunction, and other several pathologic models are in challenging state. The BOO model and cryo-injured model have a similar mechanism to induce bladder dysfunction. The BOO model also has ischemia mechanism which is similar to ischemia model. To date, for spinal cord injuries, there have been no studies published describing the grafting of stem cell into the injured bladder. Most studies have dealt with directly grafting of stem cells or bone marrow derived cells into injured spinal cord directly.

4.1. Bladder Outlet Model. Bladder outlet obstruction (BOO) caused by collagen deposit is one of the most common problems in elderly males. The collagen deposition in bladder occurs frequently during development of various pathological processes and eventually cumulates in bladder fibrosis, and finally induces a flaccid bladder. This bladder fibrosis adversely affects the smooth muscle function and the bladder compliance [33]. Bladder dysfunction after $\mathrm{BOO}$ is related 

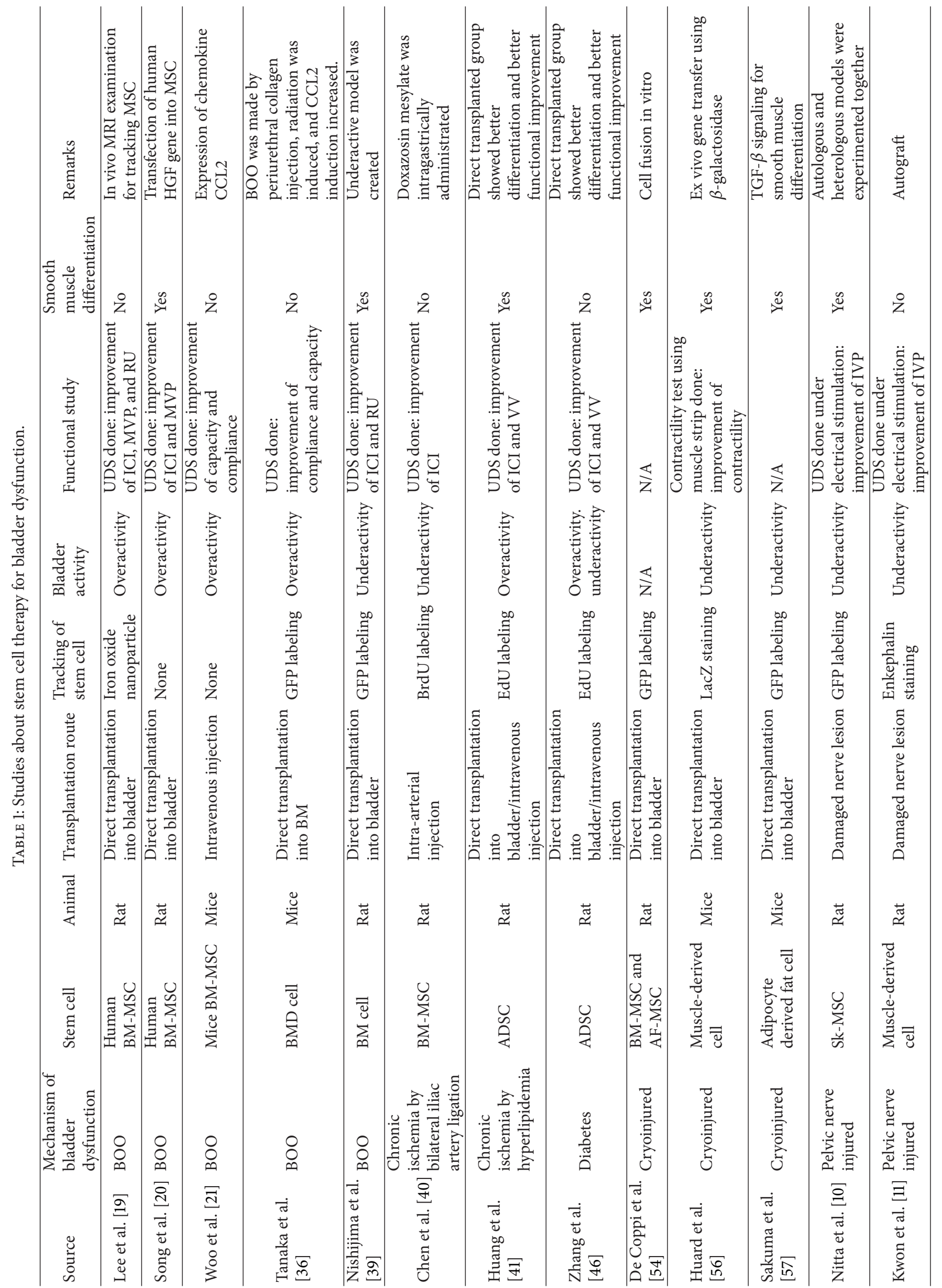


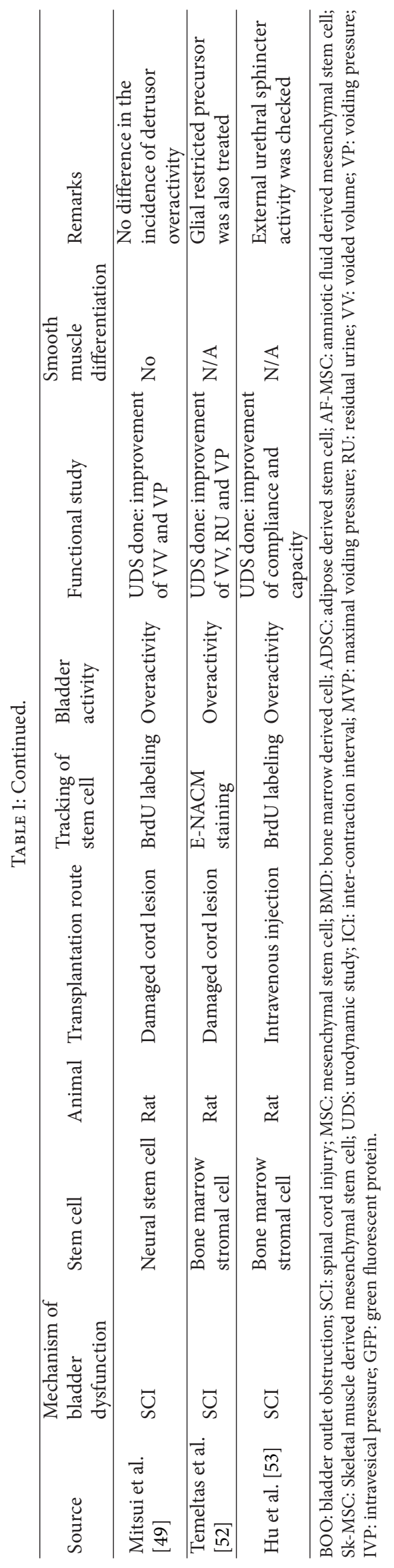


to alterations in ultrastructure properties of the smooth muscle and collagen. In bladder outlet obstruction, bladder instability was found [34]. Compensated bladder dysfunction with overactive bladder is expected after 6 weeks [33].

Recently, Lee et al. have reported that transplantation of primary human MSCs labeled with nanoparticles containing superparamagnetic iron oxide into the bladder wall of a rat BOO model inhibited bladder fibrosis and induced improvement of bladder dysfunction [19].

Growth factors have been reported in the bladder development and the remodeling of the bladder wall after outlet obstruction [35]. This finding was also demonstrated by Song et al. [20] that displayed human MSCs overexpressing HGF by pairing clonal human MSCS with HGF inhibited collagen deposition and improved cystometric parameters in $\mathrm{BOO}$ of rats.

Woo et al. [21] reported that MSCs engraftment had improved compliance compared to those without engraftment. Polymerase chain reaction revealed a 2 -fold increase in CCL2 expression, but there were no significant changes in other chemokine. Additionally, CCL2 in the BOO model was identified by Tanaka et al. [36]. In their study, bone marrow derived cells were present in the urothelial and stromal layers after BOO. An activated epidermal growth factor receptor was found in cells associated with bone marrow derived cells [36].

A possible explanation for bladder dysfunction is decreased local blood flow, which means significant tissue ischemia. Increased intraluminal pressure is thought to cause vessel compression, which is further aggravated by fibrosis and hypertrophy $[37,38]$.

Not all the BOO model results reveal overactivity. Nishijima et al. [39] showed that transplanted bone marrow cells may improve bladder contractility by differentiating into smooth muscle-like cells in underactive bladder by BOO.

The applicability of MSCs to the treatment and/or prevention of bladder dysfunction by $\mathrm{BOO}$ would provide a new, potentially powerful addition to the limited armamentarium of existing therapies.

4.2. Bladder Ischemia Model. The bladder ischemia model is established using bilateral iliac artery ligation [40] or hyperlipidemia [41]. Several studies [42] showed that artery stenosis and blood insufficiency can cause significant changes of the bladder's structure and functionality. The mechanism of ischemia-induced bladder dysfunction is complicated, which may be related to ischemic denervation. This causes M-cholinergic receptor hypersensitivity to acetylcholine [43] and results in detrusor overactivity which leads to a more ischemic state of bladder wall. Considering the high rate of ischemic changes in the elderly, it is possible that the ischemia rat model could also be used for bladder dysfunction which is caused by aging detrusor.

Chen et al. [40] reported that pathological and functional changes of the bladder ischemic model are similar to the human aging detrusor. Chen et al. [40] also reported that the injection of stem cell suspension into the common iliac artery in rats with ischemic bladder, followed by intragastric administration of doxazosin mesylate, which makes transplanted stem cells regenerate in the bladder tissue, increases the percentage of smooth muscle content and nerve cells, and improves bladder detrusor function. Huang et al. [41] showed that direct injection to the bladder or intravenous injection of ADSCs improved urodynamics and tissue parameters in the rat model of hyperlipidemia associated overactive bladder.

Azadzoi et al. [44] found that hyperlipidemia induced chronic ischemia increases transforming growth factor- $\beta 1$ in the bladder which leads to fibrosis and noncompliance.

4.3. Diabetes Model. Daneshgari et al. [45] proposed that diabetic bladder dysfunction (DBD) typically evolves in a time-dependent progression of both storage and voiding problems. The early phase of DBD manifests as detrusor overactivity, which represents leading to urinary frequency and urgency. However, over time, progressive oxidative stress and neuropathy lead to decompensation of the detrusor musculature, thereby leading to the underactive or atonic bladder.

Zhang et al. [46] reported that improved voiding function was noted in ADSCs-treated rats as compared with phosphate-buffered saline-treated rats. DBD pattern was hypocontractile bladders in their experimental model. Though some ADSCs differentiated into smooth muscle cells, paracrine pathway seems to play a main role in this process as well. This means that transplantation of ADSCs could result in reduction of apoptosis and preservation of "suburothelial capillaries network."

4.4. Spinal Cord Injured Model. Spinal cord injury (SCI) induces complete deterioration of bladder compliance, function, infection, and other lower urinary tract complications [47]. SCI rat exhibited increased bladder wall thickness that contained a larger percentage of collagen [48]. The goal of bladder treatment in patients with SCI is to reduce infections, preserve renal function, and to improve patient' quality of life. Transplantation of neural stem cells into the injured spinal cord has been reported to improve bladder function in animal models [49]. However, no study has shown whether MSCs grafting into the bladder wall can influence bladder function following SCI.

As the mature central nervous system cannot generate new neurons and glial cells, bladder functional recovery is limited following SCI. However, recent studies suggest that transplanted neural progenitor cells promote recovery of the bladder function through regeneration of the injured site [49-52]. In most of these studies, stem cells have been injected into the injured lesion directly with a needle. Hu et al. [53] showed that intravenously transplanted bone marrow stromal cells (BMSCs) survived in the L3-4 and had beneficial effects on the recovery of bladder function in the rats after spinal cord injury.

4.5. Cryo-Injured Model. The cyro-injured model induces bladder hypertrophy with loss of smooth muscle and increase of collagen which represent a similar mechanism with the BOO model [54]. The major outcome of the stem cell transplantation in the cryo-injured bladder seems to be that of preventing the increase in size of surviving smooth muscle 
cells (SMCs) along with a poor differentiation drive to SMC lineage. This can exert an important effect on the remodeling process in the injured bladder, which is characterized by the development of a compensatory SMC hypertrophy. As reported by Somogyi et al. [55], functional (and structural) impairing of innervation (and reinnervation) in the cryoinjured bladder can induce long-lasting tonic contractions to more effectively empty the bladder.

De Coppi et al. [54] showed protective effect of MSCs transplantation using AF-MSC and BM-MSC. They concluded that stem cell transplantation has a limited effect on smooth muscle cell regeneration. Instead, it can regulate postinjury bladder remodeling, possibly via a paracrine mechanism.

Huard et al. [56] showed that injected muscle-derived cells (MDCs) are capable of not only surviving in the lower urinary tract, but also improving the contractility of the bladder in cryo-injured model. They used modified MDCs which were genetically engineered to express the gene encoding $\beta$ galactosidase.

Sakuma et al. [57] showed that dedifferentiated fat cells can differentiate into smooth muscle cell lineages and contribute to the regeneration of bladder smooth muscle tissue using human adipocyte derived dedifferentiated fat cells in cryo-injured model.

4.6. Other Bladder Dysfunction Model. Nitta et al. [10] showed that significantly higher functional recovery was noted by transplantation of skeletal muscle-derived multipotent stem cells in bladder branch of the pelvic plexus (BBBP) injured model. The transplanted cells showed incorporation into the damaged peripheral nerves and blood vessels after differentiation into Schwann cells, perineurial cells, vascular smooth muscle cells, pericytes, and fibroblasts around the bladder.

Kwon et al. [11] reported that similar cell transplantation of muscle-derived cells isolated was achieved using the preplate technique, in the unilaterally transected pelvic nerve model in rats. They performed functional measurement of intravesical pressures by electrical stimulation of the transected pelvic nerve and obtained significant functional recovery through crosssectional group comparison analysis 2 weeks after transplantation.

4.7. Bladder Regeneration in Nonpathogenic Model. For bladder tissue engineering, three pioneering studies have demonstrated that embryoid body derived stem cells or BMSCs seeded on small intestinal submucosa (SIS) facilitated the regeneration of partially cystectomized bladder [58-60]. Recently hair stem cells and ADSCs seeded on bladder acellular matrix (BAM) have also shown bladder regeneration potential $[61,62]$. In studies which deal with the use of synthetic scaffolds instead of SIS and BAM, Sharma et al. reported that BMSCs seeded on poly (1,8-octanediol-cocitrate) thin film supported partial bladder regeneration [63], and Tian et al. showed that myogenic differentiated BMSCs seeded on poly-l-lactic acid scaffold exhibited bladder engineering potential [64, 65]. Likewise, poly-lacticglycolic acid seeded with myogenically differentiated human
ADSCs maintained bladder capacity and compliance when grafted in hemicystectomized rats [66].

Bladder tissue engineering using MSCs might show better results than by using differentiated cells. MSCs were shown to migrate to the bladder grafts and differentiate into SMC [67]. These cells achieved fast replacement of the grafts with appropriate neural function and less fibrosis [57].

4.8. Human Study. The human bladder is one organ to which stem cell technology could be applied. But human studies are scarce and there were no studies regarding pathologic bladder dysfunction. Studies could only be found in regards to the neobladder and urethral sphincter. Urologists need an appropriate substitute for the traditional conduits and neobladders, given their complications of adhesions, mucus formation, incomplete emptying, and metabolic and malignant transformations. Pioneering research has created artificially engineered bladder tissues using autotansplantation [68]. Urothelial and muscle cells obtained by bladder biopsy were grown in a culture for 7 weeks and transplanted in layers on a biodegradable bladder-shaped scaffold made of collagen and polyglycolic acid. During a mean follow-up of just under 4 years, all patients had improved bladder function with no major surgical or metabolic complications.

\section{Discussion}

5.1. Stem Cell Selection. Classification into embryonic or adult stem cells is useful to distinguish ethical issues associated with the destruction of an embryo to yield cells for research purposes. Whereas embryonic stem cells are considered to be pluripotent, adult stem cells are thought to be restricted in their potency by their tissue of origin. This concept remains controversial, as adult stem cells can also produce mature cells not normally seen in their tissue of origin under certain conditions. The exact molecular mechanism of this phenomenon, known as plasticity or transdifferentiation, is yet to be discovered [69]. However, the recent discovery of induced pluripotent stem cells (IPSs) has shown some light into the molecular basis of stem cells [70]. These IPSs were mostly derived from skin, but recently urinary tract derived IPSs were shown to be more efficient than skin-derived iPSCs in bladder differentiation which was demonstrated by expression of urothelial-specific markers including uroplakins, claudins, and cytokeratin and stromal smooth muscle markers including $\alpha$-smooth-muscle actin, calponin, and desmin. These disparities highlight the epigenetic differences between individual IPS lines and represent the importance of organ-specific IPSCs for tissue-specific studies [71].

Although immature (embryonic or fetal) stem cells may be more efficient than adult counterparts in points of providing the supporting acellular matrix with multipotent progenitor cells which could differentiate into distinct cell lineages, fetal-type MSCs were not superior to adult-type MSCs in terms of contributing to the formation of new differentiated SMCs or vascular cells despite the nominal higher plasticity of immature stem cells in real experiments $[54,72]$. 
5.2. Tumorigenesis. Regardless of their tissue origin, all stem cell types could not avoid the main issue of tumorigenesis and if they themselves become tumors or whether they encourage the growth/metastasis of existing tumors. While several studies on the former aspect have generated results due to tumor cell line contamination, an ever increasing number of publications are sounding the alarm on the latter issue. However, these studies relied on the use of animal models transplanted with tumor cell lines, an approach whose clinical relevance has long been questioned. This is also the main factor as to the main reason why human study is not easy.

Clinical human studies of muscle-derived cell transplantation have recently been performed in only urethral sphincter dysfunction, and no studies have been performed yet in bladder dysfunction. Eight women with stress urinary incontinence (SUI) were treated with muscle-derived stem cells [73-75].

Although, autologous transplantation of bladder stem cells could be possible and could avoid the limitation of theoretical and ethical standpoints, the exact culture conditions to direct autologous nonbladder stem cells to transdifferentiate into urothelial cells are yet to be established.

5.3. Route of Transplantation. In contrast to local injection of MSCs, intravenously administered MSCs are distributed throughout the whole animal. Furthermore, there is the concern of causing capillary clogging when larger cell types such as MSCs are infused, a complication that could result in hemodynamic compromise, interference with pulmonary gas exchange, and respiratory distress [76]. Intravenously injected MSCs are localized mainly to the pulmonary capillary bed [77]. Local injection may have a better effect than intravenous injection does. A recent study by Huang et al. [41] also showed better improvement of bladder function in the direct injection group than in the systemic injection group.

5.4. Metabolic Memory. For administration of SC, "metabolic memory" has to be considered first. It suggests that SCs derived from pathologic animals such as diabetes behave differently than those derived from healthy animals [78]. Be that as it may, it seems most likely that only individuals with a metabolic derangement leading to tissue damage will seek out this form of treatment. Hence, the diabetic or other systemically ill animal models are appropriate research subjects for preclinical research.

5.5. Gene Therapy. Although gene therapy to be efficacious and one of the promising therapeutic options, effective gene transfer into stem cells must be achieved without inducing detrimental effects on their biological properties. Although modification of MSCs to overexpress HGF has an effective means to maintain or enhance the capacity of MSCs and to be efficacious for bladder fibrosis therapy [20], the choice of vector for cell transduction should be carefully considered. The selected vector should have high transduction efficiency and should ensure stable and long-term transgene expression from the cell vehicle and be devoid of any damaging effect on cell viability.
5.6. Limitation of Experimental Study. Without intermediary examination, such as survival urodynamic or bladder biopsy at a midpoint in the experiment, also, whether stem cells may serve a more preventative or ameliorative role are too early to determine. It is hard to know whether obstructed bladders appear to undergo early signs of obstruction that are then later reversed or the pathological process is avoided altogether.

\section{Conclusions}

There are interesting results with experimental use of stem cells to treat bladder dysfunction. The use of MSCs has shown great promise in several animal studies.

Although significant challenges are still need to overcome challenges for human application, this novel technology has the potential to become a major source of cells for treatment of bladder dysfunction. In order to determine the exact role of stem cells in treatment of bladder dysfunction, more trials are needed.

\section{Acknowledgments}

This research was supported by a grant from the Research Program through the National Research Foundation of Korea (NRF) funded by the Ministry of Education, Sience, and Technology (2012-R1A1A2039317), the KRIBB Research Initiative Program (KGM4251314). The authors are indebted to Eun Ho Choi, a reference librarian at the Soonchunhyang Univetsity Medical Library, Seoul, Republic of Korea, for her help with the finding and editing of the references.

\section{References}

[1] J. R. Masters, C. Kane, H. Yamamoto, and A. Ahmed, "Prostate cancer stem cell therapy: hype or hope?" Prostate Cancer and Prostatic Diseases, vol. 11, no. 4, pp. 316-319, 2008.

[2] D.-C. Zhao, J.-X. Lei, R. Chen et al., "Bone marrow-derived mesenchymal stem cells protect against experimental liver fibrosis in rats," World Journal of Gastroenterology, vol. 11, no. 22, pp. 3431-3440, 2005.

[3] I. Sakaida, S. Terai, N. Yamamoto et al., "Transplantation of bone marrow cells reduces CCl4-induced liver fibrosis in mice," Hepatology, vol. 40, no. 6, pp. 1304-1311, 2004.

[4] J. H. Li, N. Zhang, and J. A. Wang, "Improved anti-apoptotic and anti-remodeling potency of bone marrow mesenchymal stem cells by anoxic preconditioning in diabetic cardiomyopathy," Journal of Endocrinological Investigation, vol. 31, no. 2, pp. $103-$ $110,2008$.

[5] Y. Jiang, B. N. Jahagirdar, R. L. Reinhardt et al., "Pluripotency of mesenchymal stem cells derived from adult marrow," Nature, vol. 418, no. 6893, pp. 41-49, 2002.

[6] P. A. Zuk, M. Zhu, H. Mizuno et al., "Multilineage cells from human adipose tissue: implications for cell-based therapies," Tissue Engineering, vol. 7, no. 2, pp. 211-228, 2001.

[7] G. Lin, M. Garcia, H. Ning et al., "Defining stem and progenitor cells within adipose tissue," Stem Cells and Development, vol. 17, no. 6, pp. 1053-1063, 2008.

[8] M. Albersen, T. M. Fandel, G. Lin et al., "Injections of adipose tissue-derived stem cells and stem cell lysate improve recovery 
of erectile function in a rat model of cavernous nerve injury," Journal of Sexual Medicine, vol. 7, no. 10, pp. 3331-3340, 2010.

[9] Y.-C. Huang, H. Ning, A. W. Shindel et al., "The effect of intracavernous injection of adipose tissue-derived stem cells on hyperlipidemia-associated erectile dysfunction in a rat model," Journal of Sexual Medicine, vol. 7, no. 4, part 1, pp. 1391-1400, 2010.

[10] M. Nitta, T. Tamaki, K. Tono et al., "Reconstitution of experimental neurogenic bladder dysfunction using skeletal musclederived multipotent stem cells," Transplantation, vol. 89, no. 9, pp. 1043-1049, 2010.

[11] D. Kwon, B. Minnery, Y. Kim et al., "Neurologic recovery and improved detrusor contractility using muscle-derived cells in rat model of unilateral pelvic nerve transection," Urology, vol. 65, no. 6, pp. 1249-1253, 2005.

[12] T. Tamaki, Y. Uchiyama, Y. Okada et al., "Functional recovery of damaged skeletal muscle through synchronized vasculogenesis, myogenesis, and neurogenesis by muscle-derived stem cells," Circulation, vol. 112, no. 18, pp. 2857-2866, 2005.

[13] T. Tamaki, Y. Okada, Y. Uchiyama et al., "Synchronized reconstitution of muscle fibers, peripheral nerves and blood vessels by murine skeletal muscle-derived $\mathrm{CD} 34^{-} / 45^{-}$cells," Histochemistry and Cell Biology, vol. 128, no. 4, pp. 349-360, 2007.

[14] R. Zubko and W. Frishman, "Stem cell therapy for the kidney?" American Journal of Therapeutics, vol. 16, no. 3, pp. 247-256, 2009.

[15] A. D. Sharma, T. Cantz, M. P. Manns, and M. Ott, "The role of stem cells in physiology, pathophysiology, and therapy of the liver," Stem Cell Reviews, vol. 2, no. 1, pp. 51-58, 2006.

[16] L. A. Ortiz, F. Gambelli, C. McBride et al., "Mesenchymal stem cell engraftment in lung is enhanced in response to bleomycin exposure and ameliorates its fibrotic effects," Proceedings of the National Academy of Sciences of the United States of America, vol. 100, no. 14, pp. 8407-8411, 2003.

[17] G. Chamberlain, K. Wright, A. Rot, B. Ashton, and J. Middleton, "Murine mesenchymal stem cells exhibit a restricted repertoire of functional chemokine receptors: comparison with human," PLoS ONE, vol. 3, no. 8, article e2934, 2008.

[18] M. T. Abdel Aziz, H. M. Atta, S. Mahfouz et al., "Therapeutic potential of bone marrow-derived mesenchymal stem cells on experimental liver fibrosis," Clinical Biochemistry, vol. 40, no. 12, pp. 893-899, 2007.

[19] H. J. Lee, J. H. Won, S. H. Doo et al., "Inhibition of collagen deposit in obstructed rat bladder outlet by transplantation of superparamagnetic iron oxide-labeled human mesenchymal stem cells as monitored by molecular magnetic resonance imaging (MRI)," Cell Transplantation, vol. 21, no. 5, pp. 959-970, 2012.

[20] Y. S. Song, H. J. Lee, S. H. Doo et al., "Mesenchymal stem cells overexpressing hepatocyte growth factor (HGF) inhibit collagen deposit and improve bladder function in rat model of bladder outlet obstruction," Cell Transplant, vol. 21, no. 8, pp. 1641-1650, 2012.

[21] L. L. Woo, S. T. Tanaka, G. Anumanthan et al., "Mesenchymal stem cell recruitment and improved bladder function after bladder outlet obstruction: preliminary data," Journal of Urology, vol. 185, no. 3, pp. 1132-1138, 2011.

[22] T. A. Rando, "The immortal strand hypothesis: segregation and reconstruction," Cell, vol. 129, no. 7, pp. 1239-1243, 2007.

[23] G. S. Jack, R. Zhang, M. Lee, Y. Xu, B. M. Wu, and L. V. Rodríguez, "Urinary bladder smooth muscle engineered from adipose stem cells and a three dimensional synthetic composite," Biomaterials, vol. 30, no. 19, pp. 3259-3270, 2009.
[24] D. Shukla, G. N. Box, R. A. Edwards, and D. R. Tyson, "Bone marrow stem cells for urologic tissue engineering," World Journal of Urology, vol. 26, no. 4, pp. 341-349, 2008.

[25] C. Schmidt, F. Bladt, S. Goedecke et al., "Scatter factor/hepatocyte growth factor is essential for liver development," Nature, vol. 373, no. 6516, pp. 699-702, 1995.

[26] A. Nagai, W. K. Kim, H. J. Lee et al., "Multilineage potential of stable human mesenchymal stem cell line derived from fetal marrow," PLoS ONE, vol. 2, no. 12, article e1272, 2007.

[27] M. T. Abdel Aziz, H. M. Atta, S. Mahfouz et al., “Therapeutic potential of bone marrow-derived mesenchymal stem cells on experimental liver fibrosis," Clinical Biochemistry, vol. 40, no. 12, pp. 893-899, 2007.

[28] T. Kinnaird, E. Stabile, M. S. Burnett et al., "Local delivery of marrow-derived stromal cells augments collateral perfusion through paracrine mechanisms," Circulation, vol. 109, no. 12, pp. 1543-1549, 2004.

[29] Y. Matsuda-Hashii, K. Takai, H. Ohta et al., "Hepatocyte growth factor plays roles in the induction and autocrine maintenance of bone marrow stromal cell IL-11, SDF-1 $\alpha$, and stem cell factor," Experimental Hematology, vol. 32, no. 10, pp. 955-961, 2004.

[30] T. Nakamura and S. Mizuno, "The discovery of Hepatocyte Growth Factor (HGF) and its significance for cell biology, life sciences and clinical medicine," Proceedings of the Japan Academy B, vol. 86, no. 6, pp. 588-610, 2010.

[31] C. Schmidt, F. Bladt, S. Goedecke et al., "Scatter factor/hepatocyte growth factor is essential for liver development," Nature, vol. 373, no. 6516, pp. 699-702, 1995.

[32] J. L. Spees, S. D. Olson, M. J. Whitney, and D. J. Prockop, "Mitochondrial transfer between cells can rescue aerobic respiration," Proceedings of the National Academy of Sciences of the United States of America, vol. 103, no. 5, pp. 1283-1288, 2006.

[33] A. Elbadawi, S. V. Yalla, and N. M. Resnick, "Structural basis of geriatric voiding dysfunction. IV. Bladder outlet obstruction," Journal of Urology, vol. 150, no. 5, part 2, pp. 1681-1695, 1993.

[34] W. D. Steers and W. C. De Groat, "Effect of bladder outlet obstruction on micturition reflex pathways in the rat," Journal of Urology, vol. 140, no. 4, pp. 864-871, 1988.

[35] L. S. Baskin, R. S. Sutherland, A. A. Thomson, S. W. Hayward, and G. R. Cunha, "Growth factors and receptors in bladder development and obstruction," Laboratory Investigation, vol. 75, no. 2, pp. 157-166, 1996.

[36] S. T. Tanaka, M. Martinez-Ferrer, J. H. Makari et al., "Recruitment of bone marrow derived cells to the bladder after bladder outlet obstruction," Journal of Urology, vol. 182, no. 4, pp. 17691774, 2009.

[37] M. A. Ghafar, A. G. Anastasiadis, L. E. Olsson et al., "Hypoxia and an angiogenic response in the partially obstructed rat bladder," Laboratory Investigation, vol. 82, no. 7, pp. 903-909, 2002.

[38] R. M. Levin, L. J. O’Connor, R. E. Leggett, C. Whitbeck, and P. Chichester, "Focal hypoxia of the obstructed rabbit bladder wall correlates with intermediate decompensation," Neurourology and Urodynamics, vol. 22, no. 2, pp. 156-163, 2003.

[39] S. Nishijima, K. Sugaya, M. Miyazato et al., "Restoration of bladder contraction by bone marrow transplantation in rats with underactive bladder," Biomedical Research, vol. 28, no. 5, pp. 275-280, 2007.

[40] S. Chen, H.-Y. Zhang, N. Zhang et al., "Treatment for chronic ischaemia-induced bladder detrusor dysfunction using bone marrow mesenchymal stem cells: an experimental study," International Journal of Molecular Medicine, vol. 29, no. 3, pp. 416422, 2012. 
[41] Y.-C. Huang, A. W. Shindel, H. Ning et al., "Adipose derived stem cells ameliorate hyperlipidemia associated detrusor overactivity in a rat model," Journal of Urology, vol. 183, no. 3, pp. 1232-1240, 2010.

[42] K. M. Azadzoi, "Effect of chronic ischemia on bladder structure and function," Advances in Experimental Medicine and Biology, vol. 539, part 1, pp. 271-280, 2003.

[43] P. Abrams and K.-E. Andersson, "Muscarinic receptor antagonists for overactive bladder," BJU International, vol. 100, no. 5, pp. 987-1006, 2007.

[44] K. M. Azadzoi, T. Tarcan, R. Kozlowski, R. J. Krane, and M. B. Siroky, "Overactivity and structural changes in the chronically ischemic bladder," Journal of Urology, vol. 162, no. 5, pp. 17681778, 1999.

[45] F. Daneshgari, G. Liu, L. Birder, A. T. Hanna-Mitchell, and S. Chacko, "Diabetic bladder dysfunction: current translational knowledge," Journal of Urology, vol. 182, no. 6, supplement, pp. S18-S26, 2009.

[46] H. Zhang, X. Qiu, A. W. Shindel et al., "Adipose tissue-derived stem cells ameliorate diabetic bladder dysfunction in a type II diabetic rat model," Stem Cells and Development, vol. 21, no. 9, pp. 1391-1400, 2012.

[47] M. Yoshiyama, F. M. Nezu, O. Yokoyama, W. C. de Groat, and M. B. Chancellor, "Changes in micturition after spinal cord injury in conscious rats," Urology, vol. 54, no. 5, pp. 929-933, 1999.

[48] J. Nagatomi, D. C. Gloeckner, M. B. Chancellor, W. C. DeGroat, and M. S. Sacks, "Changes in the biaxial viscoelastic response of the urinary bladder following spinal cord injury," Annals of Biomedical Engineering, vol. 32, no. 10, pp. 1409-1419, 2004.

[49] T. Mitsui, H. Kakizaki, H. Tanaka, T. Shibata, I. Matsuoka, and T. Koyanagi, "Immortalized neural stem cells transplanted into the injured spinal cord promote recovery of voiding function in the rat," Journal of Urology, vol. 170, no. 4, part 1, pp. 1421-1425, 2003.

[50] T. Mitsui, I. Fischer, J. S. Shumsky, and M. Murray, “Transplants of fibroblasts expressing BDNF and NT-3 promote recovery of bladder and hindlimb function following spinal contusion injury in rats," Experimental Neurology, vol. 194, no. 2, pp. 410431, 2005.

[51] T. Mitsui, J. S. Shumsky, A. C. Lepore, M. Murray, and I. Fischer, "Transplantation of neuronal and glial restricted precursors into contused spinal cord improves bladder and motor functions, decreases thermal hypersensitivity, and modifies intraspinal circuitry," Journal of Neuroscience, vol. 25, no. 42, pp. 9624-9636, 2005.

[52] G. Temeltas, T. Dagci, F. Kurt, V. Evren, and I. Tuglu, "Bladder function recovery in rats with traumatic spinal cord injury after transplantation of neuronal-glial restricted precursors or bone marrow stromal cells," Journal of Urology, vol. 181, no. 6, pp. 2774-2779, 2009.

[53] Y. Hu, L. M. Liao, Y. H. Ju, G. Fu, H. Y. Zhang, and H. X. $\mathrm{Wu}$, "Intravenously transplanted bone marrow stromal cells promote recovery of lower urinary tract function in rats with complete spinal cord injury," Spinal Cord, vol. 50, no. 3, pp. 202207, 2012.

[54] P. De Coppi, A. Callegari, A. Chiavegato et al., "Amniotic fluid and bone marrow derived mesenchymal stem cells can be converted to smooth muscle cells in the cryo-injured rat bladder and prevent compensatory hypertrophy of surviving smooth muscle cells," Journal of Urology, vol. 177, no. 1, pp. 369-376, 2007.
[55] G. T. Somogyi, T. Yokoyama, E. A. Szell et al., "Effect of cryoinjury on the contractile parameters of bladder strips: a model of impaired detrusor contractility," Brain Research Bulletin, vol. 59, no. 1, pp. 23-28, 2002.

[56] J. Huard, T. Yokoyama, R. Pruchnic et al., "Muscle-derived cellmediated ex vivo gene therapy for urological dysfunction," Gene Therapy, vol. 9, no. 23, pp. 1617-1626, 2002.

[57] T. Sakuma, T. Matsumoto, K. Kano et al., "Mature, adipocyte derived, dedifferentiated fat cells can differentiate into smooth muscle-like cells and contribute to bladder tissue regeneration," Journal of Urology, vol. 182, no. 1, pp. 355-365, 2009.

[58] S. Y. Chung, N. P. Krivorov, V. Rausei et al., "Bladder reconstitution with bone marrow derived stem cells seeded on small intestinal submucosa improves morphological and molecular composition," Journal of Urology, vol. 174, no. 1, pp. 353-359, 2005.

[59] D. Frimberger, N. Morales, M. Shamblott, J. D. Gearhart, J. P. Gearhart, and Y. Lakshmanan, "Human embryoid bodyderived stem cells in bladder regeneration using rodent model," Urology, vol. 65, no. 4, pp. 827-832, 2005.

[60] Y. Zhang, H.-K. Lin, D. Frimberger, R. B. Epstein, and B. P. Kropp, "Growth of bone marrow stromal cells on small intestinal submucosa: an alternative cell source for tissue engineered bladder," BJU International, vol. 96, no. 7, pp. 1120-1125, 2005.

[61] T. Drewa, R. Joachimiak, A. Kaznica, V. Sarafian, and M. Pokrywczynska, "Hair stem cells for bladder regeneration in rats: preliminary results," Transplantation Proceedings, vol. 41, no. 10, pp. 4345-4351, 2009.

[62] W.-D. Zhu, Y.-M. Xu, C. Feng, Q. Fu, L.-J. Song, and L. Cui, "Bladder reconstruction with adipose-derived stem cell-seeded bladder acellular matrix grafts improve morphology composition," World Journal of Urology, vol. 28, no. 4, pp. 493-498, 2010.

[63] A. K. Sharma, P. V. Hota, D. J. Matoka et al., "Urinary bladder smooth muscle regeneration utilizing bone marrow derived mesenchymal stem cell seeded elastomeric poly(1,8-octanediolco-citrate) based thin films," Biomaterials, vol. 31, no. 24, pp. 6207-6217, 2010.

[64] M. Nitta, T. Tamaki, K. Tono et al., "Reconstitution of experimental neurogenic bladder dysfunction using skeletal musclederived multipotent stem cells," Transplantation, vol. 89, no. 9, pp. 1043-1049, 2010.

[65] H. Tian, S. Bharadwaj, Y. Liu et al., "Myogenic differentiation of human bone marrow mesenchymal stem cells on a 3D nano fibrous scaffold for bladder tissue engineering," Biomaterials, vol. 31, no. 5, pp. 870-877, 2010.

[66] G. S. Jack, R. Zhang, M. Lee, Y. Xu, B. M. Wu, and L. V. Rodríguez, "Urinary bladder smooth muscle engineered from adipose stem cells and a three dimensional synthetic composite," Biomaterials, vol. 30, no. 19, pp. 3259-3270, 2009.

[67] A. Kanematsu, S. Yamamoto, E. Iwai-Kanai et al., "Induction of smooth muscle cell-like phenotype in marrow-derived cells among regenerating urinary bladder smooth muscle cells," American Journal of Pathology, vol. 166, no. 2, pp. 565-573, 2005.

[68] A. Atala, S. B. Bauer, S. Soker, J. J. Yoo, and A. B. Retik, "Tissue-engineered autologous bladders for patients needing cystoplasty," The Lancet, vol. 367, no. 9518, pp. 1241-1246, 2006.

[69] A. J. Wagers and I. L. Weissman, "Plasticity of adult stem cells," Cell, vol. 116, no. 5, pp. 639-648, 2004.

[70] K. Okita, T. Ichisaka, and S. Yamanaka, "Generation of germline-competent induced pluripotent stem cells," Nature, vol. 448, no. 7151, pp. 313-317, 2007. 
[71] M. Moad, D. Pal, A. C. Hepburn et al., "A novel model of urinary tract differentiation, tissue regeneration, and disease: reprogramming human prostate and bladder cells into induced pluripotent stem cells," European Urology, 2013.

[72] R. Passier and C. Mummery, "Cardiomyocyte differentiation from embryonic and adult stem cells," Current Opinion in Biotechnology, vol. 16, no. 5, pp. 498-502, 2005.

[73] L. K. Carr, D. Steele, S. Steele et al., "1-year follow-up of autologous muscle-derived stem cell injection pilot study to treat stress urinary incontinence," International Urogynecology Journal and Pelvic Floor Dysfunction, vol. 19, no. 6, pp. 881-883, 2008.

[74] M. Mitterberger, R. Marksteiner, E. Margreiter et al., "Autologous myoblasts and fibroblasts for female stress incontinence: a 1-year follow-up in 123 patients," BJU International, vol. 100, no. 5, pp. 1081-1085, 2007.

[75] M. Mitterberger, G. M. Pinggera, R. Marksteiner et al., "Adult stem cell therapy of female stress urinary incontinence," European Urology, vol. 53, no. 1, pp. 169-175, 2008.

[76] J. Gao, J. E. Dennis, R. F. Muzic, M. Lundberg, and A. I. Caplan, "The dynamic in vivo distribution of bone marrow-derived mesenchymal stem cells after infusion," Cells Tissues Organs, vol. 169, no. 1, pp. 12-20, 2001.

[77] S. Schrepfer, T. Deuse, H. Reichenspurner, M. P. Fischbein, R. C. Robbins, and M. P. Pelletier, "Stem cell transplantation: the lung barrier," Transplantation Proceedings, vol. 39, no. 2, pp. 573-576, 2007.

[78] A. Ceriello, M. A. Ihnat, and J. E. Thorpe, "The "metabolic memory": is more than just tight glucose control necessary to prevent diabetic complications?" Journal of Clinical Endocrinology and Metabolism, vol. 94, no. 2, pp. 410-415, 2009. 

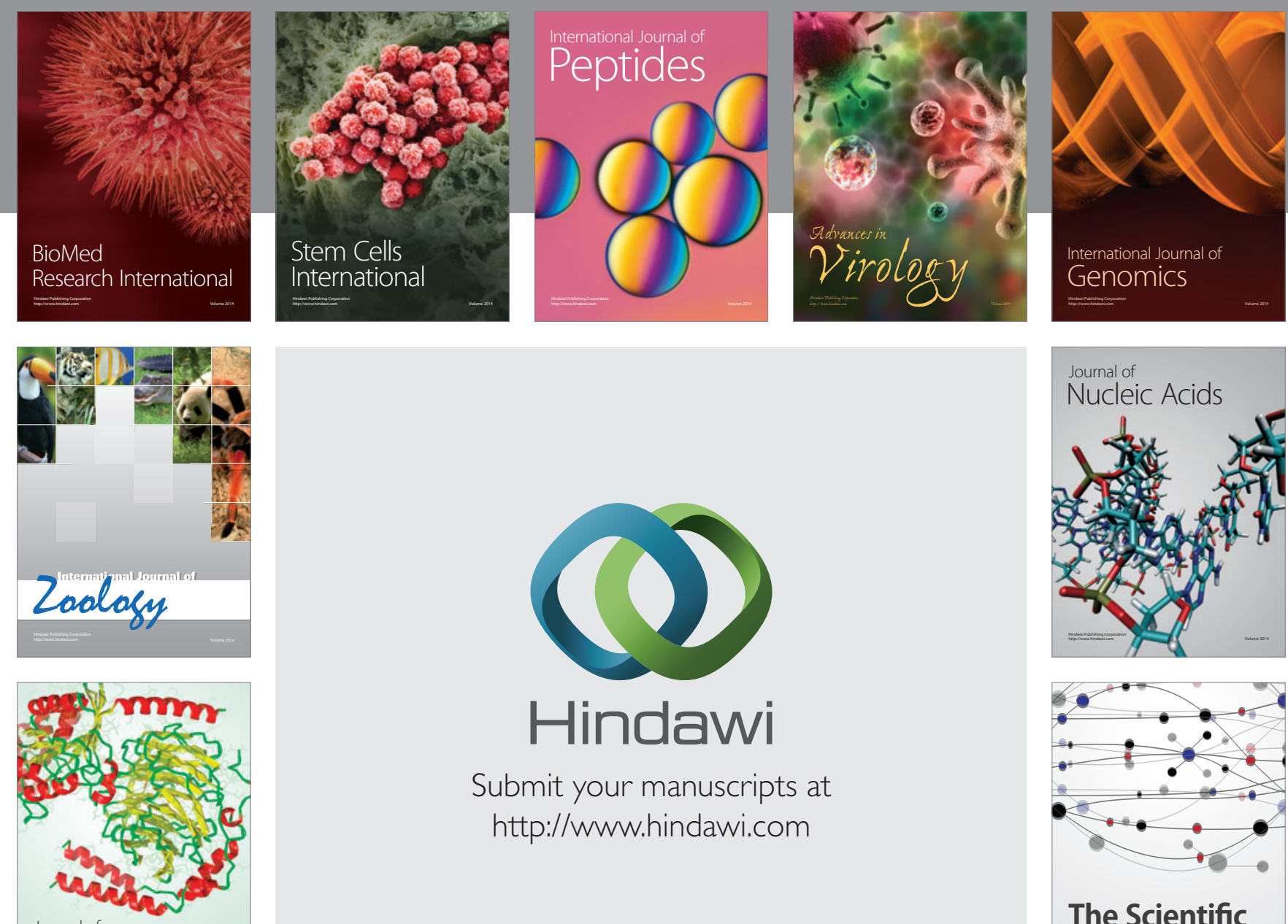

Submit your manuscripts at

http://www.hindawi.com

Journal of
Signal Transduction
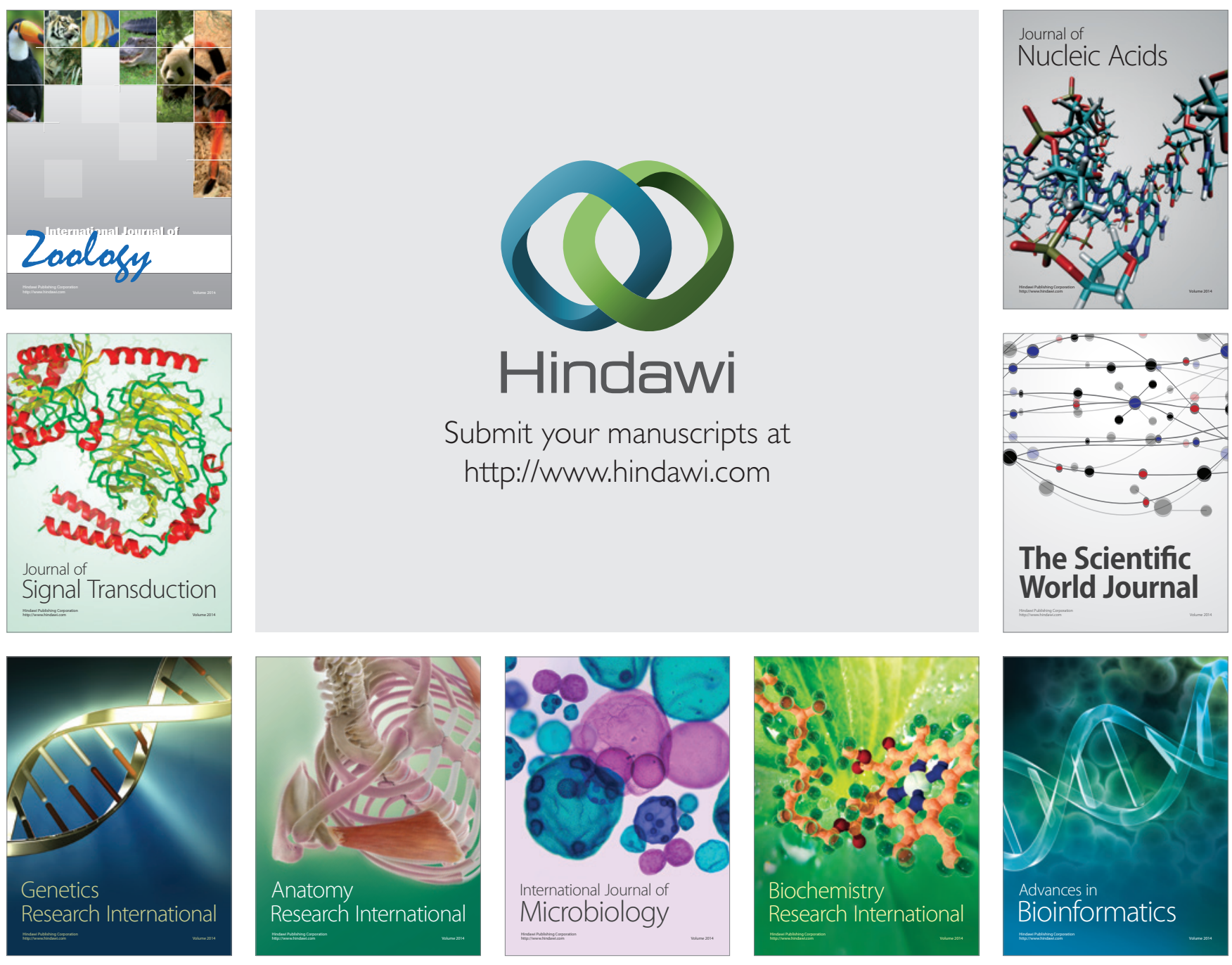

The Scientific World Journal
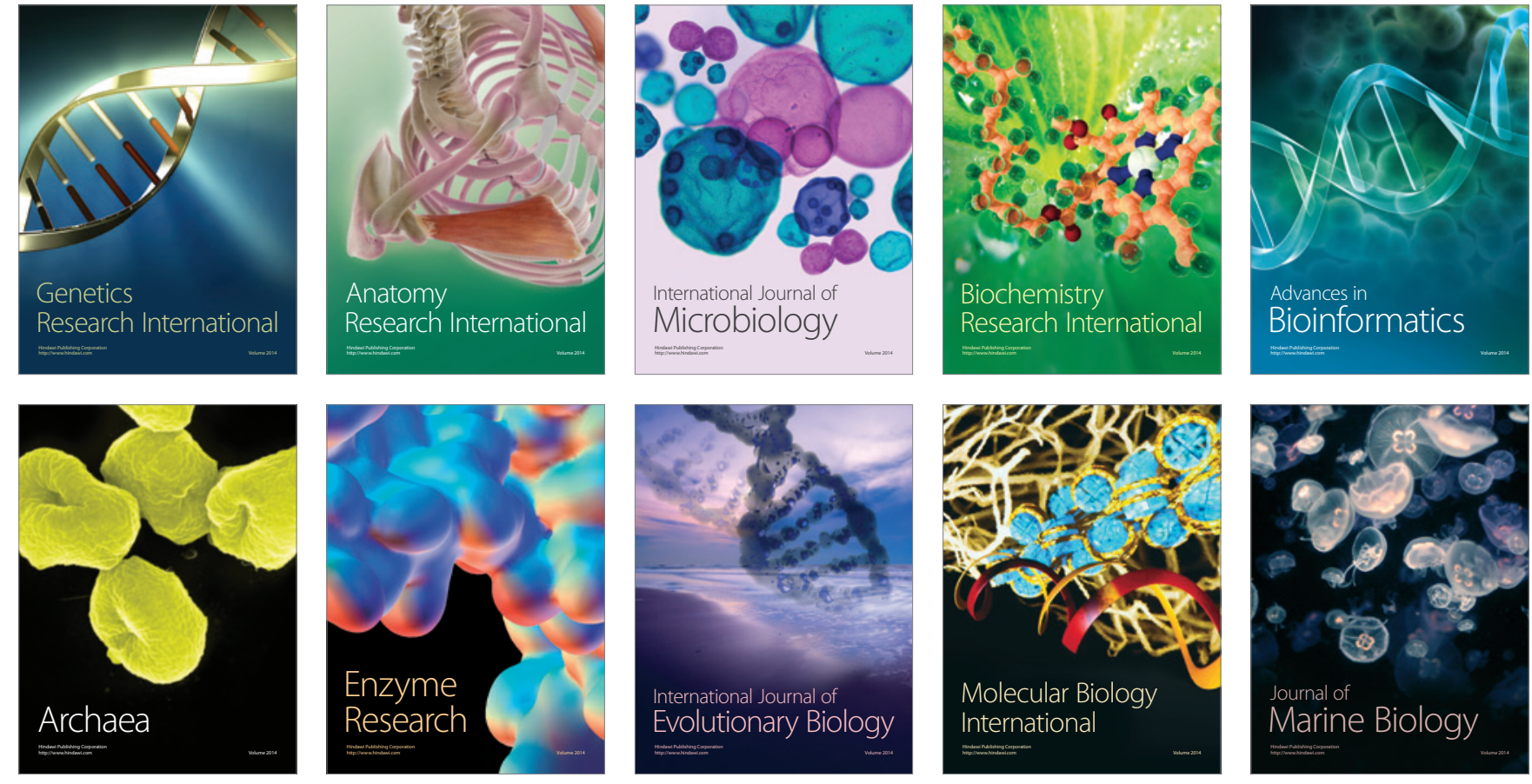